\title{
Extended High-Frequency Audiometry and Noise Induced Hearing Loss in Cement Workers
}

\author{
Giuseppina Somma, mD, ${ }^{1}$ Antonio Pietroiusti, MD, ${ }^{1}$ Andrea Magrini, MD, ${ }^{1}$ \\ Luca Coppeta, mD, ${ }^{1}$ Carla Ancona, $\mathrm{MSc}^{2}{ }^{2}$ Stefano Gardi, PhD, ${ }^{3}$ \\ Marco Messina, $\mathrm{PhD}^{3}$ and Antonio Bergamaschi, $\mathrm{MD}^{4}$
}

\begin{abstract}
Background It has been suggested that extended high-frequency audiometry (EHFA) might be more sensitive than conventional audiometry in detecting early signs of hearing impairment. However, this technique has not been adequately tested in an occupational environment. We therefore investigated the usefulness of this method in noise-exposed workers.

Methods We compared conventional frequency audiometry $(0.25-8 \mathrm{kHz})$ and EHFA $(9-18 \mathrm{kHz})$ in 184 noise-exposed and 98 non-noise-exposed workers.

Results Both methods showed significantly higher threshold levels $(P<0.05)$ in noiseexposed workers for most of the tested frequencies; however, the differences were more marked for EHFA, especially in young exposed workers. Significant differences in the EHF range were detected also in the subgroup of noise-exposed workers with normal findings at conventional audiometry. Stepwise regression analysis showed that in 21- to 40-year-old workers the noise effect was largely predominant at both conventional audiometry and EHFA, whereas in older subjects the noise effect was predominant up to $6 \mathrm{kHz}$ frequency, the effect of age being significantly greater at higher frequencies.

Conclusions These data indicate that EHFA is more sensitive than conventional audiometry in detecting noise induced hearing loss. However, hearing loss in the EHF range seems an agedependent phenomenon with progression into the lower speech range frequencies with increasing age. These changes seem to be accentuated in the early years by noise exposure, suggesting that EHFA could represent a useful preventive measure in young exposed workers. Am. J. Ind. Med. 51:452-462, 2008. ๑ 2008 Wiley-Liss, Inc.
\end{abstract}

KEY WORDS: high-frequency audiometry; noise-induced hearing loss (NIHL); occupational noise exposure; noise immission level (NIL); early detection of noise impairment

\section{INTRODUCTION}

The measures presently used in the workplace for the prevention of noise-induced hearing loss (NIHL) are

\footnotetext{
${ }^{1}$ Department of Biopathology/Occupational Medicine, Tor Vergata University, Rome, Italy

${ }^{2}$ Rome E Health Authority, Department of Epidemiology, Rome, Italy

${ }^{3}$ Italcementi Group, Department of Ecology, Bergamo, Italy

${ }^{4}$ Department of Occupational Medicine, Holy Heart Catholic University, Rome, Italy

${ }^{*}$ Correspondence to: Dr. Giuseppina Somma, Department of Biopathology/Occupational

Medicine, Tor Vergata University, via Montpellier 1, 00133 Rome, Italy.

E-mail: giusomma@libero.it

Accepted 20 February 2008

DOI 10.1002/ajim.20580. Published online in Wiley InterScience

(www.interscience.wiley.com)
}

represented by engineering and administrative controls, audiometric monitoring, and the use of personal protection devices in the workers exposed to high level noise. Although a constant decrease in the prevalence of NIHL in the workplace has been observed [Johansson and Arlinger, 2001], occupational noise exposure remains one of the most common causes of sensorineural hearing loss [Palmer et al., 2002; Nelson et al., 2005]. More effective measures are therefore needed. Since early detection of hearing loss may halt the progression of the disorder, one approach may be represented by the use of screening tests more sensitive than conventional frequency audiometry (CFA). Extended high-frequency audiometry (EHFA), defined as threshold measurement above the frequency of $8,000 \mathrm{~Hz}$, could theoretically be of clinical value for this purpose. In fact, 
although no data are currently available in humans, animal experiments have revealed that outer hair cells in the basal (high frequency) region of the cochlea are the first to be damaged by load broad-spectrum noise [Hamernik et al., 1989] and that even a small loss of these cells may cause hearing loss [Prosen et al., 1990]. In spite of these theoretical advantages, the use of EHFA has been limited until recent years by concerns about reliability of the method, due to difficulty in calibration, lack of international standards, large intersubject variability and different audiometric procedures utilized by various laboratories [Borchgrevink et al., 1996]. However, newer instruments seem to be sensitive to deviation to baseline thresholds in serial audiometric monitoring, because of their high intra-individual test-retest reliability [Borchgrevink et al., 1996], and are able to reveal variations of hearing thresholds as small as those detected at CFA [Ahmed et al., 2001].

The aim of this study was to investigate whether EHFA is more sensitive than conventional audiometry in detecting noise-induced damage in the workplace. A further analysis was conducted to evaluate the relevance of the use of personal hearing protection devices (PHD) in preventing alterations detectable at EHFA.

\section{MATERIALS AND METHODS}

In 2006, we recruited on a voluntary basis, two groups of male workers from two cement factories in Italy:

- the first group consisted of workers exposed to a daily Leq (the continuous steady noise level that would have the same acoustic energy of the actual fluctuating noise level measured over the same period of time) $\geq 85 \mathrm{~dB}$ in a weighted network $[\mathrm{dB}(\mathrm{A})]$, as determined by personal dosimetry with a $3 \mathrm{~dB}$ exchange rate.

- the second group (control group) consisted of staff workers with a daily Leq $<80 \mathrm{~dB}$. Previous occupational exposure of these workers was under the daily Leq threshold of $80 \mathrm{~dB}$.

For both groups exclusion criteria were a positive history for middle-ear disorders, familial hearing-related diseases, use of ototoxic drugs, firing guns exposure and abnormal otoscopic examination. All eligible workers agreed to participate in the study. Among 204 noise-exposed workers evaluated, 15 were excluded because of a positive history of firing guns exposure, and 3 because their ears were found to be otoscopically abnormal; among 100 non-noise-exposed workers evaluated, two subjects were excluded for a positive history of exposure to firing guns. Data were therefore analyzed for 186 noise-exposed workers and 98 non-noiseexposed controls.

Informed written consent was obtained from all subjects participating in the study. The Ethical Committee of our
Institution gave approval to the study. All the workers enrolled received a general otolaryngological examination including an otoscopic examination of the ears. A questionnaire was administered by a trained medical doctor with the objective to investigate about familial history of hearing loss, previous middle ear disease, use of potentially ototoxic drugs, history of undue exposure to excessive noise, noisy recreational activities, use of otoprotectors and smoking habits. Two measurements of blood pressure were performed in all workers and the mean of the two measurements was taken as the actual value. For the purpose of the present study, workers with a systolic level $\geq 140 \mathrm{mmHg}$ and/or a diastolic level $\geq 90 \mathrm{mmHg}$ were considered hypertensive. The workers reporting a regular use of anti-hypertensive drugs were also considered hypertensive independently from their blood pressure values.

EHFA and CFA were conducted in a sound-treated room (Mod. AP30), which ensured that maximum background noise levels were not exceeded according to the 93/42 law of the European Economic Community. EHFA and CFA were conducted after at least $18 \mathrm{hr}$ had elapsed since last noise exposure to allow recovery from any temporary hearing threshold shifts. The instrument used for the study was a clinical audiometer (Amplaid A319 high frequency; Amplifon, Milan, Italy) with standard TDH-49 headphones used for the frequency range of $250-8,000 \mathrm{~Hz}$, and Sennheiser HDA200 circumaural phones (Wedemark, Germany) used to test the EHF $9,000-18,000 \mathrm{~Hz}$ range. Measurements were made with an ascending-descending technique [ISO, 1989], in 5-dB steps, in both conventional $(0.25,0.5,1,2,3,4,6,8 \mathrm{kHz})$ and $\operatorname{EHF}(9,10,11.2,12.5,14$, $16,18 \mathrm{kHz}$ ) audiometry. All thresholds were calculated in $\mathrm{dB}$ HL. If the subject did not respond to the maximum intensity output of the high-frequency audiometer (which was $45 \mathrm{~dB}$ HL for $18 \mathrm{kHz}, 55 \mathrm{~dB}$ HL for $16 \mathrm{kHz}, 70 \mathrm{~dB}$ HL for $14 \mathrm{kHz}$, $85 \mathrm{~dB}$ HL for 12.5 and $90 \mathrm{~dB}$ HL for $11.2,10$, and $9 \mathrm{kHz}$ ) the next higher level was recorded as the hearing threshold for the subject for the statistical analysis. This level was extrapolated (following a $5 \mathrm{~dB}$ step) respectively at $50 \mathrm{~dB} \mathrm{HL}$ for $18 \mathrm{kHz}, 60 \mathrm{~dB} H L$ for $16 \mathrm{kHz}, 75 \mathrm{~dB}$ HL for $14 \mathrm{kHz}, 90 \mathrm{~dB}$ HL for 12.5 , and $95 \mathrm{~dB}$ HL for $11.2,10$ and $9 \mathrm{kHz}$, and represented a right-censored hearing threshold.

Calibration of EHF measurements in $\mathrm{dB}$ HL was provided by the manufacturing company. Reproducibility of the method was tested in a sample of 25 volunteers. The mean values between tested and retested hearing thresholds for each frequency did not differ more than $10 \%$ for both conventional and high frequencies. In detail, in each individual subject, we did not observe differences higher than $5 \mathrm{~dB}$, except for one subject who showed a $10 \mathrm{~dB}$ discordance between the two measurements at the $18 \mathrm{kHz}$ frequency.

The normality of the audiometric data was tested by computing the measures of skewness and kurtosis. The 
distribution of the hearing thresholds of all subjects was unimodal and positively skewed, so a natural logarithmic transformation was applied to normalize the distribution. Consequently, parametric tests of significance were applied to transformed data. To control the effect of age on hearing thresholds and better evaluate noise effects on the high frequencies, exposed and non-exposed subjects were grouped by age decade into four groups $(21-30 ; 31-40$; 41-50, 51-60 years); a similar age-based subgroup division has been performed by others [Ahmed et al., 2001]. Descriptive statistics, means, medians, standard deviations (SDs) and standard errors of the means (SEs) were calculated to describe central tendencies in each group. Student's $t$-test for independent samples and the median test were used to evaluate the difference between means and medians of the individual binaural hearing loss measurements in each age group. A comparison of the averages of multiple thresholds $(3-4-6 ; 9-10-11.2 ; 12.5-$ 14-16) was also conducted to reduce issues of multiple comparisons. Categorical variables were evaluated by means of $\chi^{2}$ test.

Stepwise linear regression analysis (forward selection procedure) was used to assess the most important predictors of hearing threshold: all the workers recruited in the study were included in the model. A further stepwise linear regression analysis was also conducted dividing the workers in two subgroups (those aged 21-40 years and those aged 41-60 years) in order to assess whether the above mentioned predictors may have a different relevance in workers belonging to different age groups. Different regression models were performed for each of the high and conventional frequencies tested. Age (years), noise immission level (NIL), smoking habits (yes, other) and hypertension (yes, no) were used as independent variables in the regression analysis. The NIL [Leq, dB (A)] combines the noise exposure level and the duration of noise exposure, and it was calculated for both exposed and non-exposed subjects as it follows: $\mathrm{NIL}=\mathrm{Leq}+\mathrm{k} \log _{10}\left(\mathrm{~T} / \mathrm{T}_{0}\right)$, where $\mathrm{T}$ is the number of years of noise exposure, $\mathrm{T}_{0}$ is the reference time of 1 year and $\mathrm{k}$ is a constant estimated to be 10 [Burns and Robinson, 1970]. A $P$-value of $<0.05$ was taken as the level of statistical significance.

To investigate the possible role of EHFA as an early indicator of noise damage, the means of high frequencies hearing thresholds of noise-exposed subjects with any value $<25 \mathrm{~dB}$ at conventional hearing thresholds $(0.5-8 \mathrm{kHz})$ were compared to that of non-exposed subjects.

The importance of the use of PHD ("yes" = always; no = "not always or never") was tested by the study of interaction among deteriorated hearing thresholds and the use of otoprotectors. Data were analyzed using the statistical computer program Stata (Release 9).

\section{RESULTS}

All noise-exposed workers included in the study had been employed for at least 1 year before enrolment. The mean age of the non-exposed subjects was 36.5 years whereas the mean age of the noise-exposed group was 39.8 years $(P=\mathrm{ns})$, moreover, no racial or ethnic difference was found between the two groups of workers. Table I shows the prevalence of smoking, hypertension and NIL values among the two groups, by age decade.

The means of binaural hearing loss measurements in each individual were compared between the two groups, by age decade. As shown in Table II, for each age decade, exposed subjects had a significantly higher mean hearing threshold than non-exposed subjects at most of the high frequencies tested (with the exception of the age decades $41-50$ years at 16 and $18 \mathrm{kHz}$ and 51-60 years at 14 and $18 \mathrm{kHz} ; P<0.05)$. In particular, the largest difference between hearing thresholds was found at $16 \mathrm{kHz}$ for subjects aged $21-30$, at $14 \mathrm{kHz}$ for the 31- to 40-year-old subjects, at $12.5 \mathrm{kHz}$ for the 41 - to 50 -year-old subjects and at $10 \mathrm{kHz}$ for the oldest group of subjects (Fig. 1, panel A). Less marked differences were observed for conventional frequencies (Table II and Fig. 1, panel B). The comparison of the means of three groups of multiple thresholds

TABLE I. Main Characteristics of the Subjects Participating in the Study

\begin{tabular}{|c|c|c|c|c|c|c|c|c|}
\hline \multirow{2}{*}{$\begin{array}{l}\text { Age group (years) } \\
\text { Noise exposure }\end{array}$} & \multicolumn{2}{|c|}{$21-30$} & \multicolumn{2}{|c|}{$31-40$} & \multicolumn{2}{|c|}{$41-50$} & \multicolumn{2}{|c|}{$51-60$} \\
\hline & Non-exp 24 & Exp 21 & Non-exp 38 & Exp 80 & Non-exp 33 & Exp 69 & Non-exp 3 & Exp 16 \\
\hline Mean age $\pm S D$ (years) & $27 \pm 2.6$ & $28 \pm 2.3$ & $34.5 \pm 2.8$ & $35.7 \pm 2.5$ & $44.4 \pm 2.9$ & $44.8 \pm 2.8$ & $52.7 \pm 1.8$ & $53.8 \pm 2$ \\
\hline \multirow[t]{3}{*}{ Smoking \% } & No, 54.2 & No, 47.7 & No, 44.7 & No, 37 & No, 66.6 & No, 26.1 & No, 66.7 & No, 12.5 \\
\hline & Yes, 37.5 & Yes, 33.3 & Yes, 31.6 & Yes, 35 & Yes, 27.3 & Yes, 37.7 & Yes, 0 & Yes, 26.3 \\
\hline & Ex, 8.3 & Ex, 19 & Ex, 23.7 & Ex, 28 & Ex, 6.1 & Ex, 36.2 & Ex, 33.3 & Ex,61.2 \\
\hline \multirow[t]{2}{*}{ Hypertension \% } & No, 100 & No, 95.2 & No, 97.3 & No, 88.8 & No, 90.9 & No, 64.2 & No, 33.3 & No, 56.2 \\
\hline & Yes, 0 & Yes, 4.8 & Yes, 2.7 & Yes, 11.2 & Yes, 9.1 & Yes, 35.8 & Yes, 66.7 & Yes, 43.8 \\
\hline $\mathrm{NIL}$ mean $\pm \mathrm{SD}$ & $81.7 \pm 4.3$ & $93.2 \pm 5$ & $85.5 \pm 2.9$ & $98.9 \pm 3.9$ & $87.9 \pm 2.5$ & $102.8 \pm 4.5$ & $89.1 \pm 1.3$ & $103.1 \pm 4.8$ \\
\hline
\end{tabular}




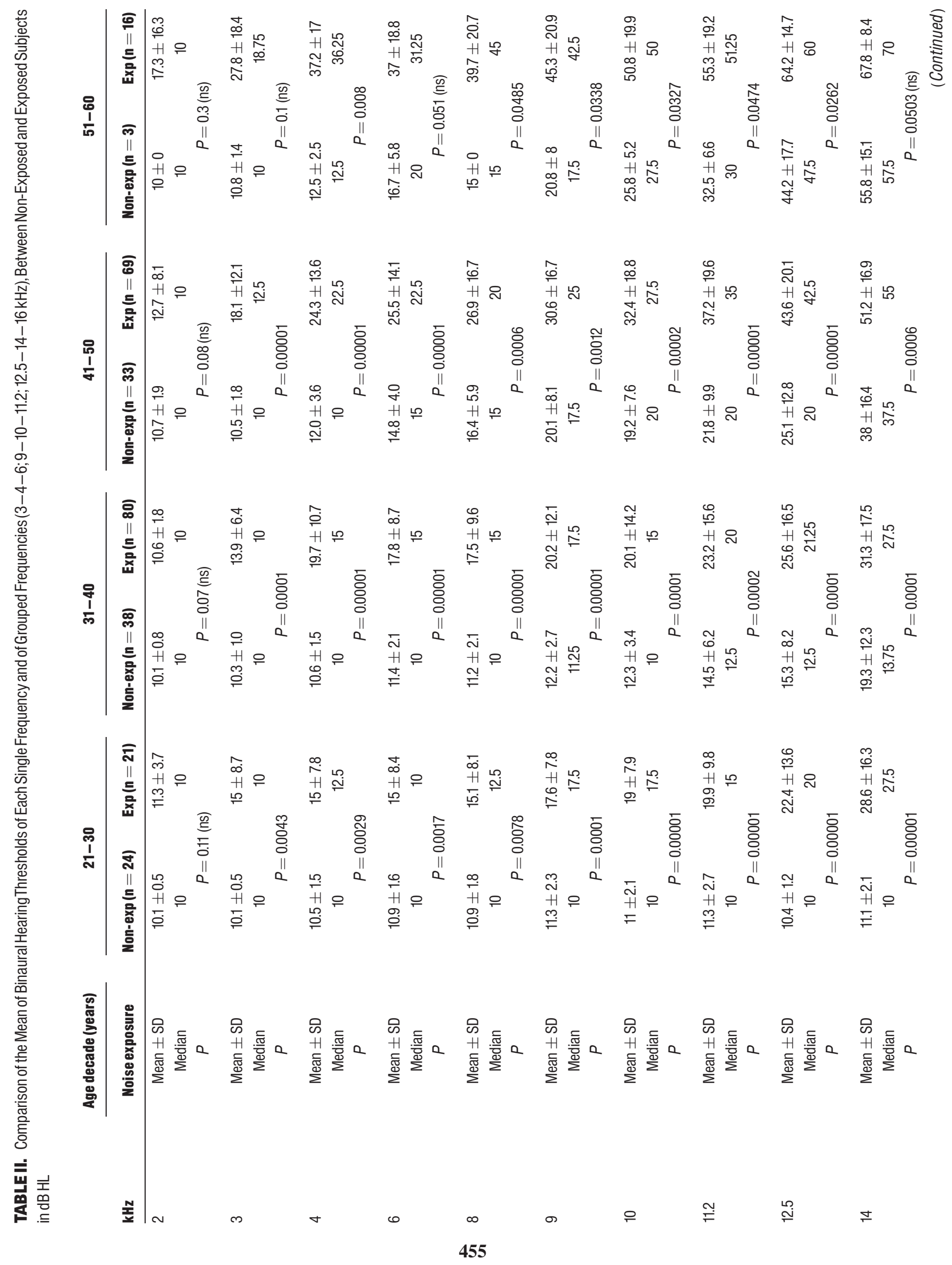




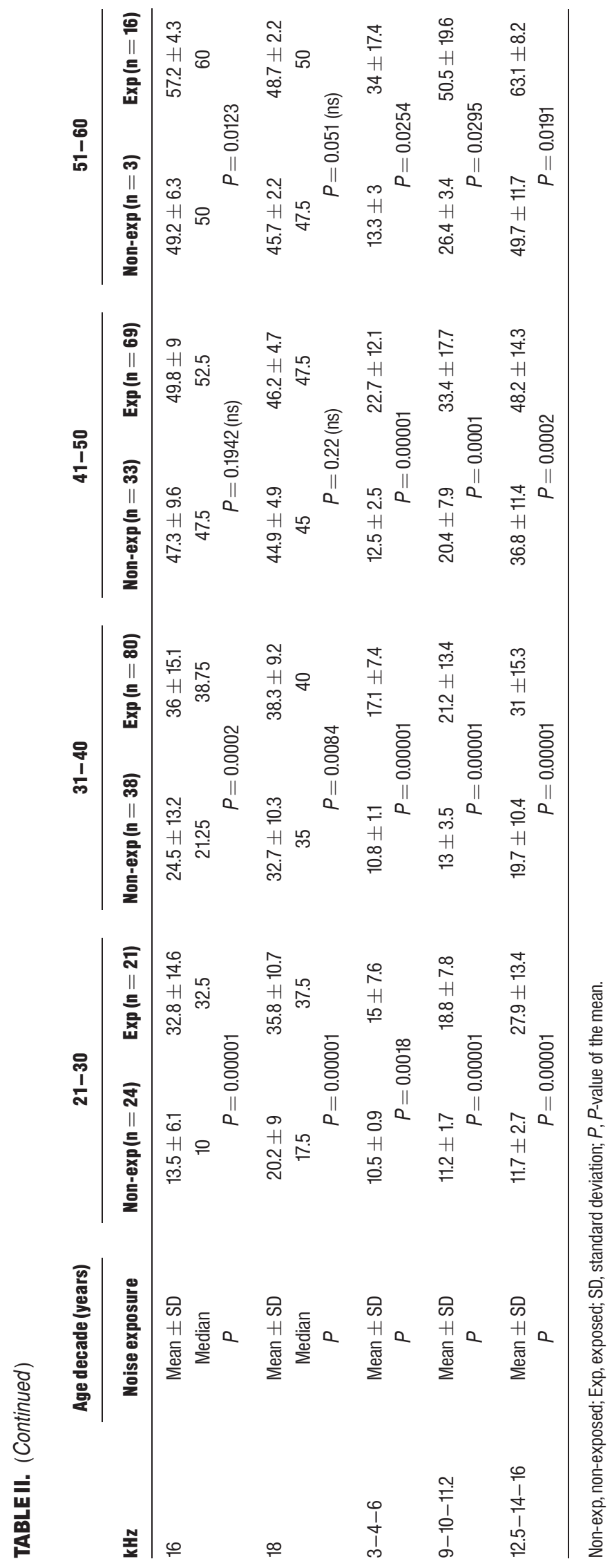

(3-4-6 kHz; 9-10-11.2 kHz; and $12.5-14-16 \mathrm{kHz}$ ) between exposed and non-exposed workers confirmed these findings (Table II).

All non-exposed workers who were younger than 40 years responded to all the given pure tones at both conventional audiometry and EHFA, whereas $6 \%$ of the exposed workers belonging to the same age group did not respond to the maximum amplitude for the $16 \mathrm{kHz}$ pure tone, and $20 \%$ for the $18 \mathrm{kHz}$. Similar differences were observed among those older than 40 years: the 36 non-exposed subjects were able to respond up to $14 \mathrm{kHz}$, the percentage decreasing to $86 \%$ and $72 \%$ for the 16 and $18 \mathrm{kHz}$ pure tones, respectively. On the other hand, all 85 exposed subjects responded to all the given pure tones up to $12.5 \mathrm{kHz}$, the percentage decreasing to $93 \%, 69 \%$, and $51 \%$, respectively for the 14,16 , and $18 \mathrm{kHz}$ pure tones.

Figure 2 shows the results of the stepwise regression analysis. In detail, Figure 2 shows the contribution of age, NIL, smoking and hypertension to hearing impairment, with the multiple correlation coefficient $\left(\mathrm{R}^{2}\right)$ for age, noise, smoking and hypertension at the $3-18 \mathrm{kHz}$ frequencies. All four predictors were positively correlated to the hearing thresholds, although age and noise were by far the two most important predictors (panel A). In 21- to 40-year-old workers the noise effect was largely predominant at all tested frequencies except for the $18 \mathrm{kHz}$ frequency: range $86 \%$ (at 16 and $14 \mathrm{kHz}$ ) to $100 \%(3-12.5 \mathrm{kHz}$; panel B); in older subjects the noise effect was predominant up to $6 \mathrm{kHz}$ frequency, whereas at higher frequencies the effect of age was significantly greater (panel C).

\section{HFA as an Early Indicator of NIHL}

To investigate the possible role of HFA as an early indicator of NIHL, the means of binaural hearing thresholds at the high frequencies of noise-exposed subjects with any value $<25 \mathrm{~dB}$ at conventional hearing thresholds $(0.5-8 \mathrm{kHz})$ were compared to that of the non-exposed subjects. As shown in Figure 3 the noise-exposed subjects were found to have higher mean hearing thresholds at all tested high frequencies. All differences were statistically significant $(P<0.05)$ for the 21 - to 30-year-old workers; for the second age group (31-40 years) all differences were statistically significant with the exception of 16 and $18 \mathrm{kHz}$ frequencies. On the other hand, in the 41-50 years age group the statistically significant differences were present only at two frequencies $(12.5-14 \mathrm{kHz})$ while no significant statistical difference was found for the oldest workers (51-60 years).

\section{Use of Otoprotectors}

As expected, the use of otoprotectors by noise-exposed workers was associated with lower hearing thresholds (the 
A

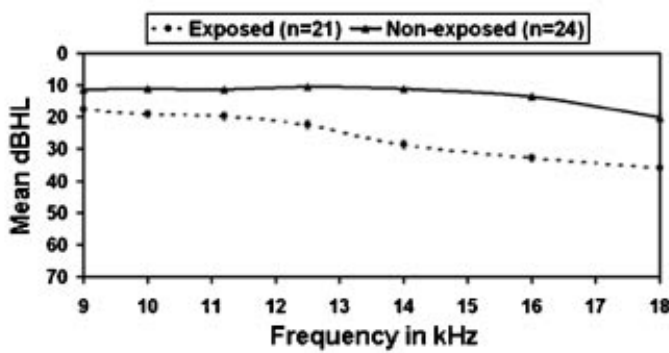

Age Group 41. 50 years

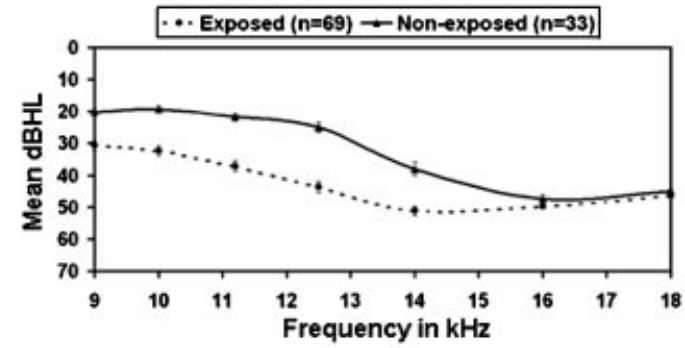

B

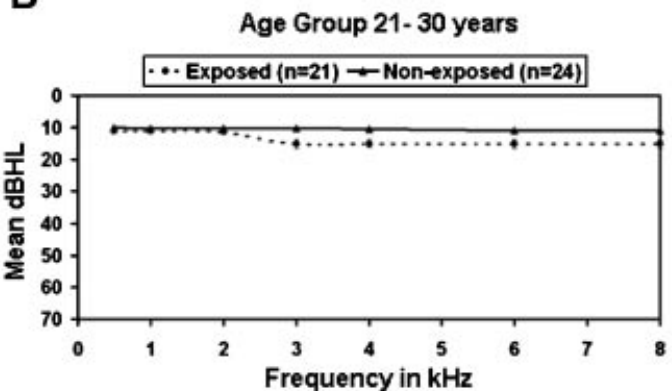

Age Group 41- 50 years

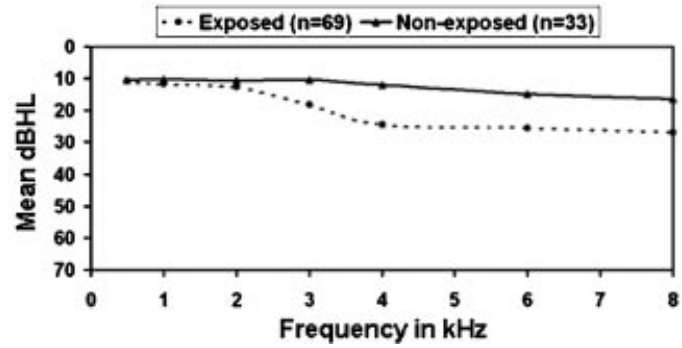

Age Group 31.40 years

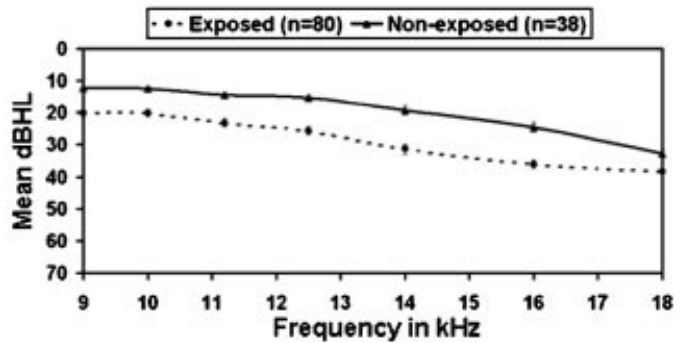

Age Group 51- 60 years

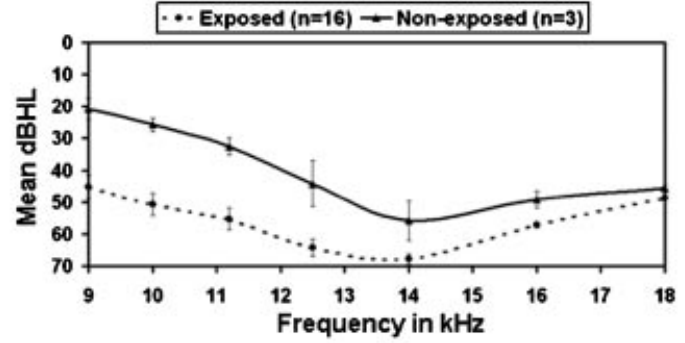

Age Group 31- 40 years

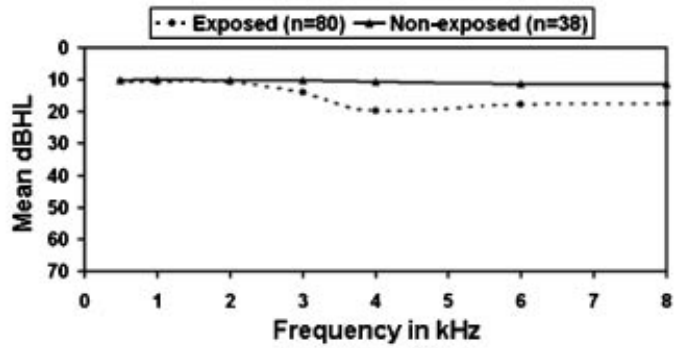

Age Group 51.60 years

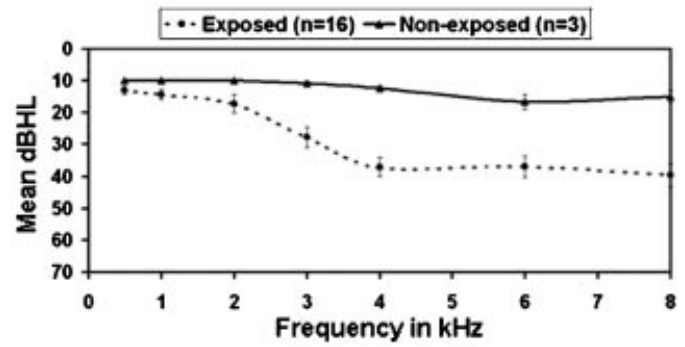

FIGURE 1. Mean hearing thresholds of exposed subjects versus non-exposed subjects in different age groups. Error bars refer to standard error of the mean. PaneIA: EHFA; panel B: conventional audiometry.

regression coefficient range was $31-40 \%$ ) at both conventional audiometry and EHFA in the range $9-12.5 \mathrm{kHz}$ $(P<0.001)$. On the other hand, the effectiveness of the use of otoprotectors decreased for the highest frequencies $(14-18 \mathrm{kHz})$ with the regression coefficient ranging from $10 \%$ to $25 \%$ (Table III). This finding however, might be in part related to the contribution given by the ceiling effect due to censorship (being the limit of the maximum output of the audiometer $70 \mathrm{~dB}$ for $14 \mathrm{kHz}, 55 \mathrm{~dB}$ for $16 \mathrm{kHz}, 45 \mathrm{~dB}$ for the $18 \mathrm{kHz}$ ).

Nevertheless, when compared to non-exposed workers, exposed workers using otoprotectors had significantly higher hearing thresholds at EHFA, for all tested frequencies in the 21-30 years age group, for 5 out of 7 tested frequencies in the 

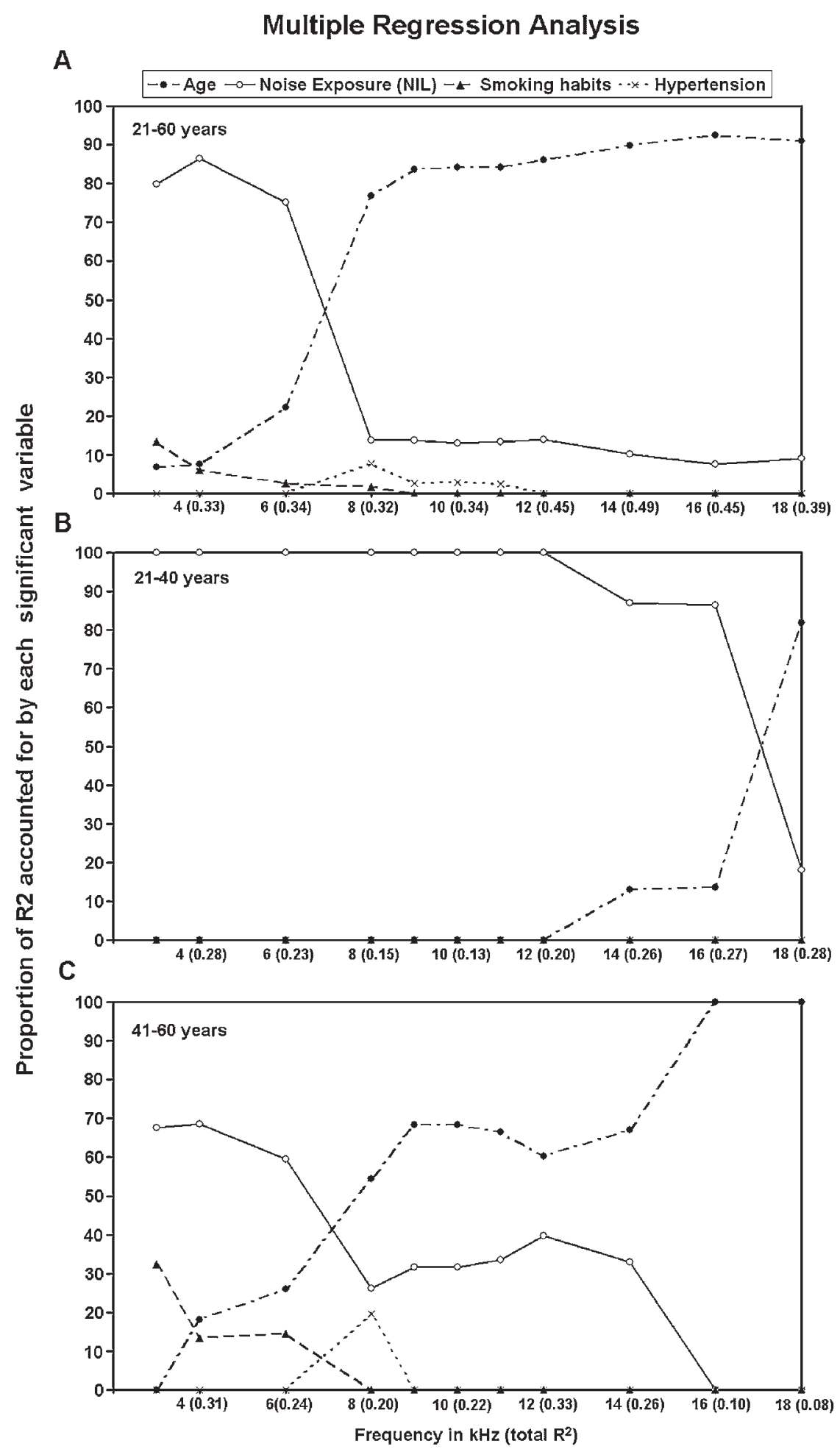

FIGURE 2. Multiple regressionanalysis showing the contribution of age, noise exposure (NIL), smoking and hypertensionto hearing impairment at conventional audiometry and EHFA in all examined workers (paneI A), in the subgroup 21 - 40 years old (panel B), and in those aged 41-60 years (panelC). 

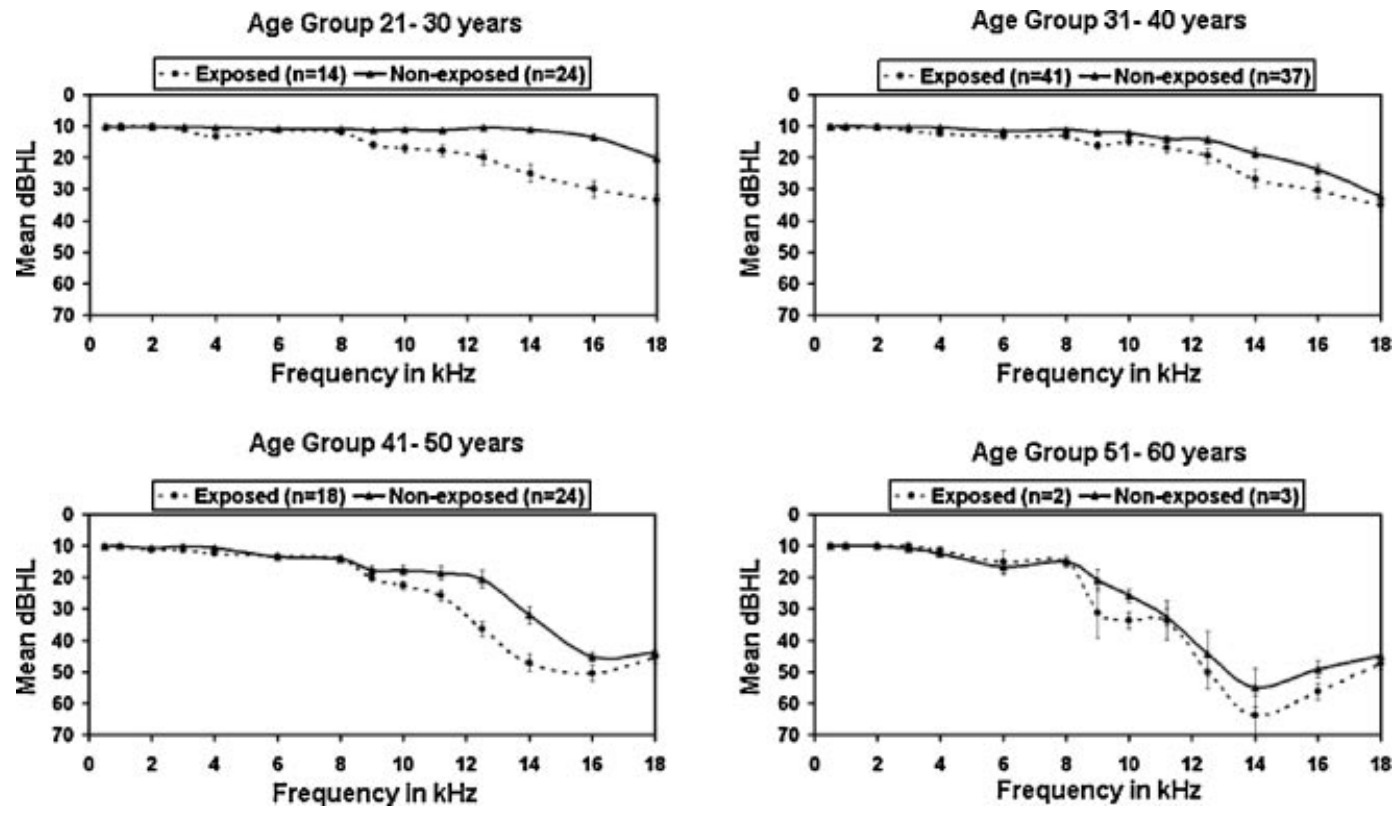

FIGURE 3. Mean hearing thresholds of exposed subjects versus non-exposed subjects with any value $<25 \mathrm{~dB}$ at conventional hearing thresholds. Error bars refer to standard error of the mean.

31-40 years age group, and for 2 out of 7 tested frequencies in the 41-50 years age group. No significant difference was detected in workers older than 50 years (Table IV).

\section{DISCUSSION}

Occupational physicians' program for the prevention of NIHL usually includes conventional audiometry. With this method, the first signs of hearing impairment are detected in

TABLE III. Effectiveness of the Protection of the Otoprotectors for the $3-18 \mathrm{kHz}$ Frequencies (Regression Coefficients, $P$ Values, and 95\% Confidence Intervals-Cl)

\begin{tabular}{lccc} 
kHz & Coefficient & $\boldsymbol{P}$ & CI \\
\hline 3 & 0.33 & 0.0001 & $0.20-0.47$ \\
4 & 0.38 & 0.0001 & $0.23-0.53$ \\
6 & 0.31 & 0.0001 & $0.18-0.45$ \\
8 & 0.31 & 0.0001 & $0.17-0.46$ \\
9 & 0.34 & 0.0001 & $0.20-0.48$ \\
10 & 0.33 & 0.0001 & $0.18-0.48$ \\
11.2 & 0.40 & 0.0001 & $0.25-0.55$ \\
12.5 & 0.36 & 0.0001 & $0.20-0.52$ \\
14 & 0.25 & 0.001 & $0.10-0.40$ \\
16 & 0.21 & 0.001 & $0.09-0.33$ \\
18 & 0.10 & 0.010 & $0.02-0.18$ \\
\hline
\end{tabular}

Regression coefficients are adjusted for age, smoking and history of hypertension and indicate the percentage of reduction of NIHL by hearing protection. the 4-6 kHz range. It has been suggested, however, that more subtle changes in pure-tone thresholds are not detected by this method [Hone et al., 2003]. Therefore, complementary or alternative methods have been evaluated. In particular, data for distortion product otoacoustic emissions (DPOE) and EHFA are available. DPOE has the theoretical advantage of not being based on the subjective judgment of the investigated individual, and has been demonstrated to be somewhat more sensitive than standard pure tone audiometry in detecting early changes due to noise exposure [Seixas et al., 2004, 2005]. Its extensive use, however, is limited by the fact that this technique is time-consuming and requires high technical skill.

EHFA may be a reliable option, since this technique is easy to be conducted, requires the same instrument used for standard audiometry and only a few minutes to be performed. Problems with inter- and intrasubject variations have been strongly reduced with the use of newer instruments. Indeed, we observed a comparable reproducibility for both conventional and high frequencies with the instrument used in the present study.

The potential usefulness of EHFA in noise-induced damage is indirectly supported by studies on drug-induced ototoxicity, which have shown that high frequency thresholds generally appear to be affected first, with spread of hearing loss into the conventional frequency range throughout the course of treatment [Dreschler et al., 1985; Fausti et al., 1992, 1993; Tange et al., 1985].

Our findings indicate that hearing loss in the EHF range is an age-dependent phenomenon with progression into the 


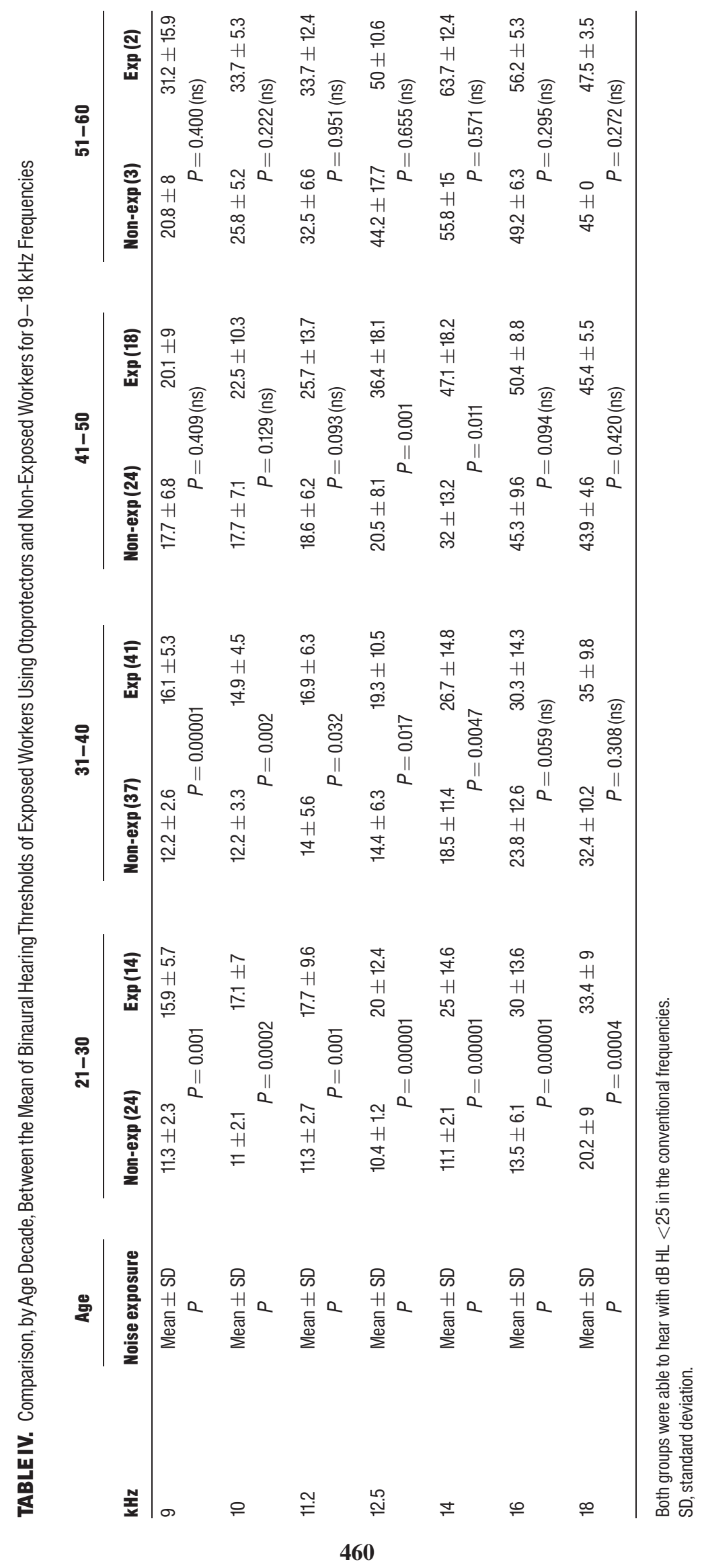


lower frequencies of the speech range with increasing age and that these changes are accentuated in the early years by noise exposure. Hence, EHFA could be useful for assessment of workers younger than 40 years, since after 40 years, age appears to play an increasing role and the contribution of work exposures may be overwhelmed by age-related hearing loss.

In young subjects (those younger than 40 years) the most affected frequencies seem to be 14 and $16 \mathrm{kHz}$, and it is possible that testing these frequencies only, can give as much information as testing all the frequencies, reducing the time of the test. Prospective studies are, however, needed to support the role of EHFA for a more general assessment of risk for NIHL.

Few data are available in the literature on the possible role of EHF testing as an early indicator of work-related hearing loss. To our knowledge, during the last 10 years, only five studies have been published on this topic. All of them suggested the usefulness of this method. However, the generalization of the data derived from these studies is limited by some methodological issues, such as the very high noise level ( $>95 \mathrm{~dB}$ ) [Wang et al., 2000], the low number of enrolled subjects [Turkkahraman et al., 2003; Porto et al., 2004; Kazkayasi et al., 2006] or the presence of important mismatches between cases and controls [Ahmed et al., 2001]. Taken together, however, these reports give support to our findings, considering that we were careful in avoiding the above reported sources of bias.

Our findings may have implications even for the policy of hearing protection. We found, in fact, that impairment of hearing at high frequencies was detectable even in workers using otoprotection. The finding is not surprising, since it has been recently reported that personal protection devices may not completely prevent NIHL [Daniell et al., 2006]. Development of devices able to protect workers from the high frequency impairment should be implemented. We cannot exclude that misreporting of otoprotective measures by exposed workers may have influenced our findings. If this was indeed the case, the use of high frequencies might help to identify these workers and to administer them appropriate educational support.

The present study has the inherent limitations of all cross-sectional studies. In particular, only prospective studies may prove the causal relationship between noise at work and deterioration of high frequency thresholds. Furthermore, our data cannot be confidently extrapolated to women, since only men were employed in the two cement factories included in the study.

However, we feel that the involvement of all eligible subjects in the workplace, gives strength to our findings. Finally, although all workers included in the study lived in the same geographic area, and the vast majority of the nonexposed subjects were manual workers not exposed to noise (e.g., crane operators, laboratory personnel, control room staff and storehouse personnel) or unskilled office workers, for whom a level of education and of income similar to the exposed subjects is highly probable, we cannot exclude that factors linked to their different tasks might have played a role in determining the hearing status.

In conclusion, this study suggests that EHFA may represent a useful tool for the detection of early sub-clinical changes of NIHL in the workplace, mainly in young workers. At the current stage of knowledge, its usefulness in the individual should be assessed by serial monitoring showing a progression of high frequency hearing impairment, as observed in studies on drug ototoxicity.

\section{ACKNOWLEDGMENTS}

The work was in part supported by a grant from Tor Vergata University Fondi di Ateneo 60\% 2005.

\section{REFERENCES}

Ahmed HO, Dennis JH, Badran O, Ismail M, Ballal SG, Ashoor A Jerwood D. 2001. High-frequency $(10-18 \mathrm{kHz})$ hearing thresholds: Reliability, and effects of age and occupational exposure. Occup Med (Lond) 51:245-258.

Borchgrevink HM, Hallmo P, Mair IWS. 1996. Extended highfrequency hearing loss from noise exposure. In: Axelsson A Borchgrevink HM, Hamernik RP, Hellstrom PA, Henderson D, Salvi RJ, editors. Scientific basis of noise-induced hearing loss. New York: Thieme. 299-312 p.

Burns W, Robinson DW. 1970. Hearing and noise in industry. London: HMSO.

Daniell WE, Swan SS, McDaniel MM, Camp JE, Cohen MA, Stebbins JG. 2006. Noise exposure and hearing loss prevention programmes after 20 years of regulations in the United States. Occup Environ Med 63: $343-351$.

Dreschler WA, vd Hulst RJ, Tange RA, Urbanus NA. 1985. The role of high-frequency audiometry in early detection of ototoxicity. Audiology 24:387-395.

Fausti SA, Henry JA, Schaffer HI, Olson DJ, Frey RH, McDonald WJ. 1992. High-frequency audiometric monitoring for early detection of aminoglycoside ototoxicity. J Infect Dis 165:1026-1032.

Fausti SA, Henry JA, Schaffer HI, Olson DJ, Frey RH, Bagby GC, Jr. 1993. High-frequency monitoring for early detection of cisplatin ototoxicity. Arch Otolaryngol Head Neck Surg 119:661666.

Hamernik RP, Patterson JH, Turrentine GA, Ahroon WA. 1989. The quantitative relation between sensory cell loss and hearing thresholds. Hear Res 38:199-211.

Hone SW, Norman G, Keogh I, Kelly V. 2003. The use of cortical evoked response audiometry in the assessment of noise induced hearing loss. Otolaryngol Head Neck Surg 128:257-262.

International Organization for Standardization Acoustics. 1989. Pure tone audiometric test methods. Part 1: Basic pure tone air and bone conduction threshold audiometry. Geneva, Switzerland: ISO 8253-1.

Johansson M, Arlinger S. 2001. The development of noise-induced hearing loss in the Swedish County of Ostergotland in the 1980s and 1990s. Noise Health 3:15-28. 
Kazkayasi M, Yetiser S, Ozcelik S. 2006. Effect of musical training on musical perception and hearing sensitivity: Conventional and high-frequency audiometric comparison. J Otolaryngol 35:343348 .

Nelson DI, Nelson RY, Concha-Barrientos M, Fingerhut M. 2005. The global burden of occupational noise-induced hearing loss. Am J Ind Med 48:446-458.

Palmer KT, Griffin MJ, Syddal HE, Davis A, Pannett B, Coggon D. 2002. Occupational exposure to noise and the attributable burden of hearing difficulties in Great Britain. Occup Environ Med 59:634639 .

Porto MA, Gahyva DL, Lauris JR, Lopes AC. 2004. Audiometric evaluation in extended high frequencies of individuals exposed to occupational noise. Pro Fono 16:237-250.

Prosen CA, Moody DB, Stebbins WC, Smith DW, Sommers MS, Brown JN, Altschuler RA, Hawkins JE, Jr. 1990. Apical hair cells and hearing. Hear Res 44:179-193.
Seixas NS, Kujawa SG, Norton S, Sheppard L, Neitzel R, Slee A. 2004 Predictors of hearing threshold levels and distortion product otoacoustic emissions among noise-exposed young adults. Occup Environ Med 61:899-907.

Seixas NS, Goldman B, Sheppard L, Neitzel R, Norton S, Kujawa SG. 2005. Prospective noise induced changes to hearing among construction industry apprentices. Occup Environ Med 62:309-317.

Tange RA, Dreschler WA, van der Hulst RJ. 1985. The importance of high-tone audiometry in monitoring for ototoxicity. Arch Otorhinolaryngol 242:77-81

Turkkahraman S, Gok U, Karlidag T, Keles E, Ozturk A. 2003. Findings of standard and high-frequency audiometry in workers exposed to occupational noise for long durations. Kulak Burun Bogaz Ihtis Derg 10:137-142.

Wang Y, Yang B, Li Y, Hou L, Hu Y, Han Y. 2000. Application of extended high frequency audiometry in the early diagnosis of noiseinduced hearing loss. Zhonghua ER Bi Yan Hou Ke Za Zhi 35:26-28. 